\title{
Linkage Frameworks: An Exploration Tool for Complex Systems in Ecosystem-Based Management
}

\author{
Leonie A. Robinson and Fiona E. Culhane
}

\begin{abstract}
A key barrier to achieving Ecosystem-Based Management (EBM) is dealing with complexity of social-ecological systems (SES). SES incorporate ecological, social and economic factors that interact within and between each other. Carrying out quantitative analyses to aid decision making in these systems is often too complex and/or limited by data. We describe a complementary approach, the use of Linkage Frameworks, that can be used to explore EBM. Linkage frameworks are essentially networks of elements or nodes found in a system, with links representing the interactions between those nodes. In an EBM context, nodes might include human activities, their pressures, biodiversity components, the ecosystem services supplied in that ecosystem, and the users or beneficiaries of the activities and services supported. Interactions could highlight, for example, which activities introduce which pressures, which biodiversity components are linked to which human activities through their pressures, and which ecosystem services are supplied by each biodiversity component. This approach can help to structure systems conceptually, allowing consideration of complex systems in decision making and facilitating communication between, for example, scientists, ecosystem managers and stakeholders. We discuss the strengths, assumptions and limitations of the tool, drawing on examples from aquatic ecosystems across Europe.
\end{abstract}

\section{Lessons Learned}

- Although dealing with the complexity of SESs can be challenging, there are advantages to persevering. We show, using a linkage framework approach, that retaining the complexity of the system in analyses to inform decision making, can provide different perspectives on EBM questions.

- Linkage Frameworks are specified for specific systems and specific issues or problems. It is important that users are aware of this as the specification will affect the understanding of the system.

L. A. Robinson $(\varangle) \cdot$ F. E. Culhane

School of Environmental Sciences, University of Liverpool, Liverpool, UK

e-mail: leonie.robinson@liverpool.ac.uk; F.Culhane@liverpool.ac.uk 
- Decisions for EBM cannot be made on the LF approach alone. However, exploration of LFs can be used to highlight where complementary detailed, data driven studies are needed.

\section{Needs to Advance EBM}

- Effort needs to be made to include analyses that retain the complexity of the SES so that we can move forward in understanding indirect links and unintended consequences of EBM management decisions. These do not need to be data driven but do need to be supported by detailed, data driven studies to support the assumptions made.

- Non-linearity needs to be included in the risk assessment approaches that are supported by weighted Linkage frameworks. To date much of the existing work assumes that risk accumulates linearly as you 'add up' components that act together within a SES. In reality some cumulative effects may be antagonistic, whilst others may be synergistic, and the type of interaction may also vary in space due to environmental conditions.

\section{Introduction}

Complexity is a defining issue in dealing with environmental problems, sometimes called 'wicked' problems, where diverse interests and conflicts from ecological, economic and social elements meet (Rittel and Webber 1973; Game et al. 2014). Dealing with complexity in Ecosystem-Based management (EBM) is an ongoing barrier at all stages from identifying drivers of ecological issues to implementing management measures (see G. Piet et al. 2020 for further discussion of this complexity). While complexity is sometimes seen as a problem that needs to be solved or avoided in EBM, systems thinking tells us to embrace it (Mitchell 2009). Indeed, by retaining complexity in our assessments, we can discover emerging properties of social ecological systems (SES). This can help to overcome the traditional problems of environmental management, where narrow thinking can lead to poor decision making and unintended consequences that are often the result of these emerging properties (Yodzis 2001).

Retaining complexity in EBM does have its limitations. Data and resource needs are often much higher and uncertainty in the outcome can limit interpretation. In order to move forward pragmatically with a systems approach, it is necessary to start at the broadest level with a description of the entire system that includes both high level, often qualitative or semi-quantitative, analyses with detailed analyses of specific parts of the SES, as has been described in many chapters of this volume (e.g. see Elliott and O'Higgins (2020)).

In this chapter we use the construction of Linkage Frameworks (LF) to describe SESs, defining all relevant SES parts and the links between them. We explain what an LF is and explore how it can be used to underpin Ecosystem-Based Management (EBM). Linkage frameworks are essentially networks of elements (or nodes) found in a system, with links representing the interactions between those elements. In an 
EBM context, nodes might include human activities, their pressures, biodiversity components, the ecosystem services supplied in that ecosystem, and the users or beneficiaries of the activities and services supported. Interactions could highlight, for example, which activities introduce which pressures, which biodiversity components are linked to which human activities through their pressures, and which ecosystem services are supplied by each biodiversity component. This approach can help to structure systems conceptually, allowing consideration of complex systems in decision making and facilitating communication between, for example, scientists, ecosystem managers and stakeholders. We will discuss the strengths, assumptions and limitations of the tool, drawing on examples from aquatic ecosystems across Europe and covering the following topics:

- Constructing linkage frameworks-elements, typologies and links

- Linkage frameworks as a visual tool for EBM

- Exploring the system-linkages, connectivity and modularity

- Weighting links - categorical and numerical approaches

- Linkage frameworks and Risk Assessment for EBM

\section{Constructing Linkage Frameworks-Elements, Typologies and Links}

Constructing a linkage framework requires defining the elements of the SES, the typologies within each element, and the links between these. The elements are the high-level building blocks of the framework that set out the relevant architecture for the EBM assessment being undertaken. For example, Box 1 illustrates a LF consisting of six major elements, all of which are important for exploring EBM options around achieving Europe's Marine Strategy Framework Directive (MSFD) (EC 2008). Box 2 considers a simpler assessment, where there were only three key elements in the LF explored. Here, the objective was to understand the dependencies of ecosystem services on marine species and habitats (Fiona E. Culhane et al. 2018).

Each component of the elements making up the LF can then be further defined for the system in question using a typology (for example, 'fishing' might be one component of the 'Activity' element of the LF). The typologies used should be complete for each element of the system, but the level of detail required will reflect the scope of the assessment being undertaken (e.g. whether to work with specific species or broad biotic groups). Typologies may build on existing work, and this may be especially important where the questions being explored have a context set out in policy, or where a structure is needed that is relevant to information or data collected at a specific level of detail (F. Culhane et al. 2020). 


\section{Box 1 Choosing Elements of the Linkage Framework Relevant for the Objectives of the Assessment}

In the project Options for Delivering Ecosystem Based Marine Management (ODEMM), a linkage framework approach was used as the starting point for implementation of Ecosystem-Based Management (EBM). The main goals of the EBM assessment here were related to achieving the objectives of Europe's Marine Strategy Framework Directive (MSFD), i.e. Good Ecological Status (GES) for 12 key descriptors, which include, for example: 'seafloor integrity ensures functioning of the system', 'elements of food webs ensure long-term abundance and reproduction', and 'biodiversity is maintained' (EC 2008). We were interested in the elements of the system that would affect achievement of these objectives (sectors (covering the major human activities affecting marine ecosystems in the study system), the pressures introduced by any one of those sectors, and the state of ecological components), how different management options acting on these increased likelihood of achieving GES, and how achievement of GES for those 12 descriptors might affect ecosystem services supported by the ecosystem. Thus, in this context, six key elements formed the overall structure of the system, whilst governance was defined for each EBM scenario explored (Fig. 1) (see further elaboration on this in Culhane et al. 2020).

For the example in Box 1, the MSFD lists activities, pressures, and ecological components relevant for European marine environments, as well as policy objectives as a list of 12 key descriptors (EC 2008). These lists formed the starting point for typologies (classifications or lists of components) of four of the seven key elements depicted by the boxes in Fig. 1 (see White et al. 2013). A typology of ecosystem services was developed in the absence of a suitable marine typology (BöhnkeHenrichs et al. 2013), and a typology of management options was devised to select relevant EBM measures (see Fig. 1 in Piet et al. 2015). For the Box 2 example, the Common International Classification of Ecosystem Services (CICES) (HainesYoung and Potschin 2013, 2018) was the starting point for the development of a marine ecosystem service typology. In addition, a holistic typology of serviceproviding units, built on existing EU typologies of habitats and biotic groups, was constructed. The explicit aim being to document how the combination of a specific habitat and biotic group supports the capacity of marine ecosystems to supply services (see detail in Culhane et al. 2018).

Having established typologies for each element within the LF of interest, the links between all components specified can be identified, initially in a qualitative way, simply showing where a link exists. Linkages are usually assigned based on expert judgement, underpinned by evidence from published studies where possible, and a set of matrices developed showing all links in the study system (e.g. https://www. odemm.com/content/linkage-framework). 


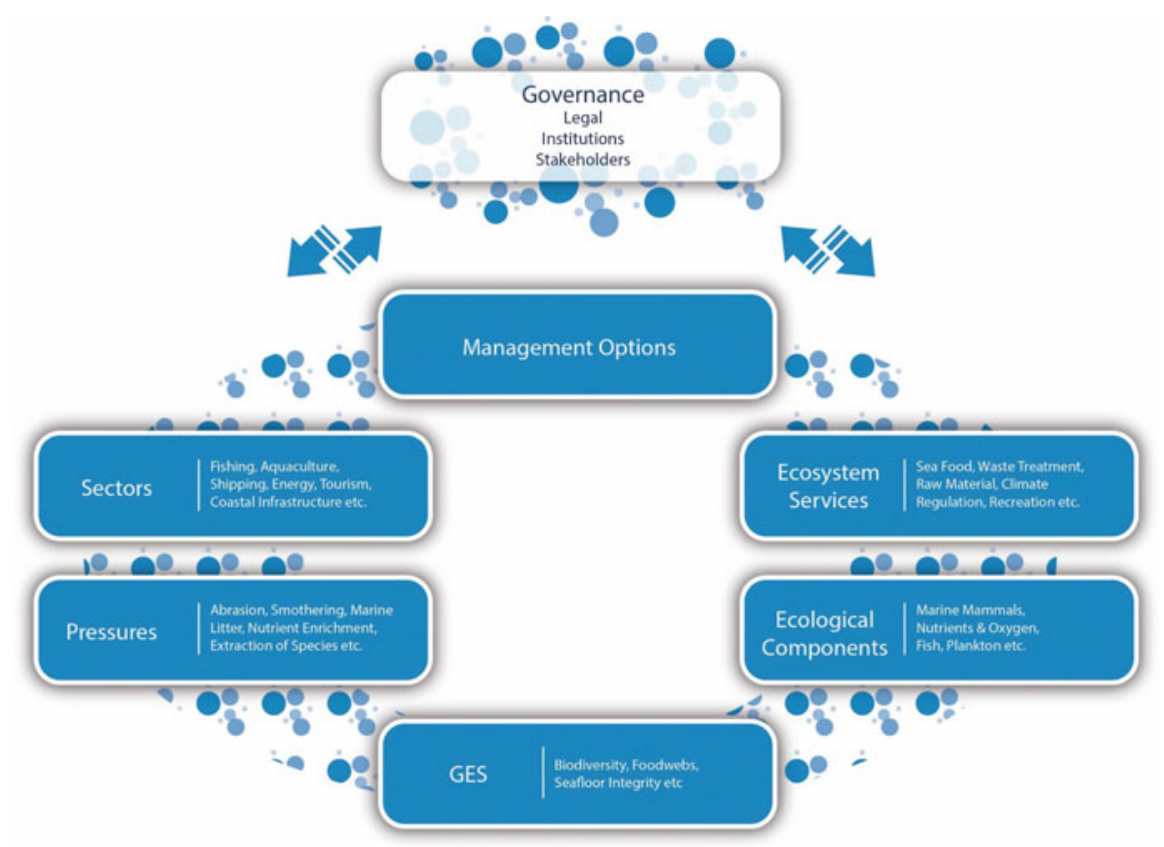

Fig. 1 Blue boxes represent the major elements that were considered in this EBM study system where achievement of Good Ecological Status (GES; EC 2008) was the overarching objective, and examples of the components included in the underlying typologies for key elements are given. This diagram shows that a linkage framework is non-linear, as represented by the centre circle: linkages between elements are specified dependent on the issue being tackled at the time. All of the elements lie within the relevant governance setting, which determines the policy drivers, legal obligations, who is involved, and who makes the decisions (from Robinson et al. 2014)

In the Box 1 example, links between sectors and pressures were identified, where evidence suggests a pressure (such as noise pollution) can be introduced by a sector, whilst links between pressures and ecological components indicate that the pressure in question can affect that aspect of biodiversity (e.g. a specific habitat type). Links were specified between management options and sectors, pressures and ecological components, indicating where management might act (e.g. to reduce activity of a sector or restore state of an ecological component). Links between pressures, ecological components and GES descriptors indicated that the state of those pressures and/or ecological components can affect the potential to achieve the objective of a linked GES descriptor. Finally, links were specified between ecological components and ecosystem services, where the state of an ecological component is known to underpin the supply of a service.

In the Box 2 example, links between habitats and biotic groups indicate that the biotic group in question (e.g. demersal fish) would spend some or all of its life in a specified habitat. Whilst links between biotic groups and ecosystem services signify 
that there is evidence that the functioning of that biotic group in some way contributes to the supply of the linked ecosystem services.

\section{Box 2 Service Providing Units: The Importance of Typologies That Reflect the Objectives of the Study}

This example focuses on the work required to develop typologies within a linkage framework that best describe the functioning of marine ecosystems in terms of how they supply ecosystem services. Culhane et al. (2018) developed a typology of ecosystem components, or service providing units (SPUs), that fulfilled the following criteria:

1. SPUs reflect that biodiversity provides services through its functioning i.e. they explicitly specified and included biota and not just habitats. For example, while saltmarsh or mudflats provide erosion prevention, this does not recognise that it is the plants, tubes of invertebrates and films of microphytobenthos and microorganisms that actually supply the service. This point is important to recognise to both understand how the service is supplied and to understand how to protect or restore the service.

2. SPUs reflect that biota can vary in functioning between habitats and locations i.e. they explicitly included habitats to give SPUs a location and an abiotic identity. For example, floating clumps of macroalgae and attached algae both provide habitat for juvenile fish, however, only macroalage that forms belts around the coast also supplies coastal protection. This point is important to recognise the spatial aspects of ecosystem service supply.

3. SPUs reflect differences in vulnerability to human pressures i.e. vulnerability varies between biota and between habitats for the same biota. For example, epifauna is more sensitive to fishing pressure than infauna within habitats, and deep sea habitats are less exposed but also less resilient to fishing pressure than shallow habitats are. In considering the sustainability of ecosystem service supply, it is important to be able to recognise vulnerabilities to human pressures (Fig. 2).

Considering these three criteria led to the development of SPUs that consisted of a habitat and a biotic group. These units could then be linked to the specific services that they supply.

Complex SES considered in EBM may be represented by many thousands of linkages in a LF approach. This alone can highlight the complexity of the system and can be utilised to identify pathways through the system (see next section). Holistic EBM is complex by nature (Piet et al. 2020); the linkage framework approach allows scientists and advisors to visualise and structure the landscape within which advice is required and decisions are made. This can be of great importance where there is a lot of information or data available for some aspects of the SES in question 


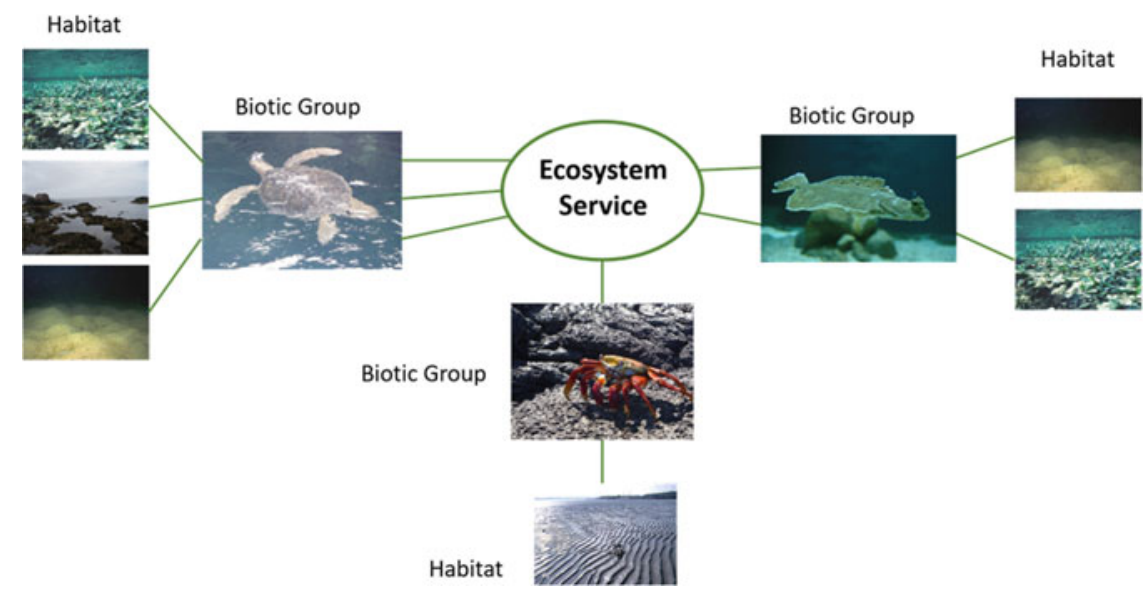

Fig. 2 Illustration representing a number of marine service providing units (SPUs), where each is made up of a habitat and a biotic group and lines represent the linkages between ecosystem services and the SPUs that supply them

and little for others. For example, Robinson et al. (2019)) used a LF approach to structure a stakeholder workshop. All activities operating and all relevant components of biodiversity in a study system were considered in terms of influence on stakeholder goals, rather than just those well known to stakeholders. This allowed barriers and opportunities in EBM to be identified.

It is important to note that the elements chosen, typologies defined within these, and basis on which linkages are defined must be clearly articulated in terms of the scope and rationale used. Ultimately, a LF provides a specific definition of a study system and it is critical that it is understood in this context.

\section{Linkage Frameworks as a Visual Tool for EBM}

The linkage framework approach provides a powerful tool for visualisation of the complex systems underlying EBM. One can start by illustrating the overall system (e.g. Fig. 1, Box 1), continuing to illustrate how the SES can be interrogated to reveal relevant linkages dependent on the topic of interest. Expanding on the example in Box 1, Fig. 3a highlights those elements of the marine SES that would be relevant in terms of considering status of, and threats to the MSFD's GES (Good Ecological Status) policy descriptors, whilst Fig. $3 \mathrm{~b}$ builds on this, showing the linkages from management options that could act to reduce threat to GES. By working through a series of such illustrations, the framework within which EBM options sit can be contextualised for experts and non-experts alike, highlighting the interdependencies of the system. 


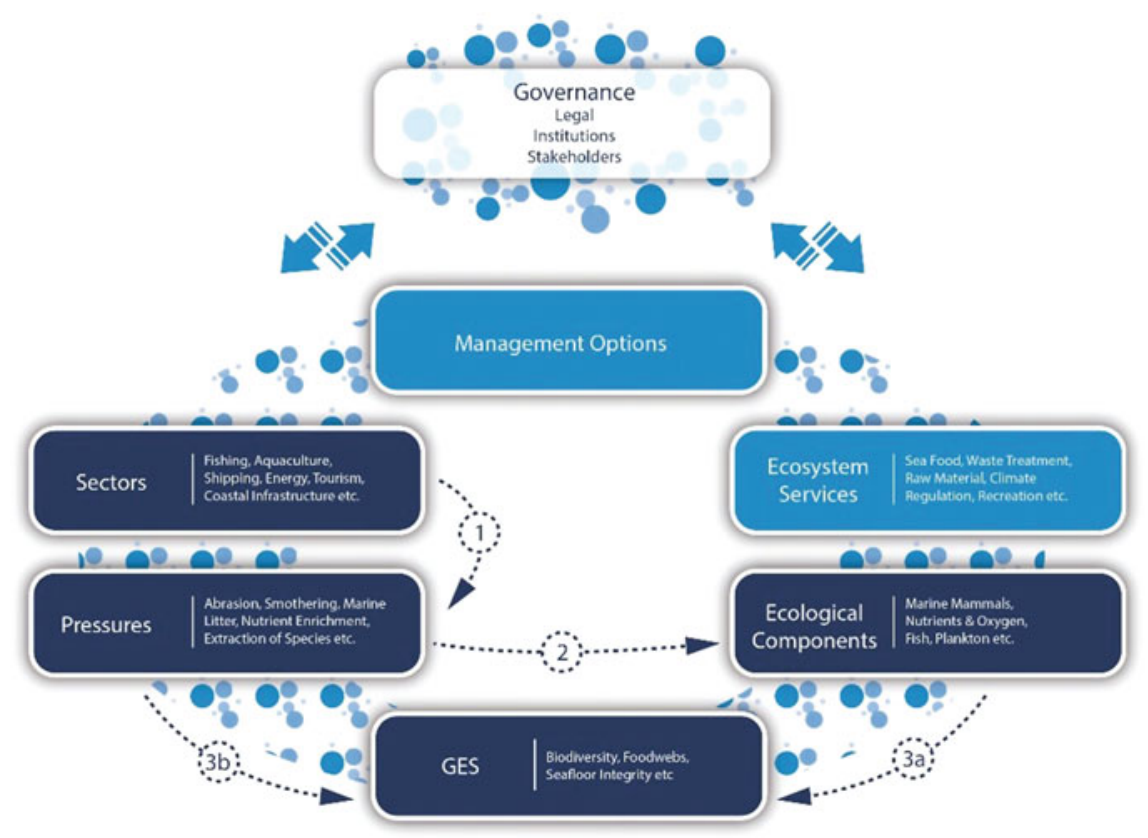

(a)

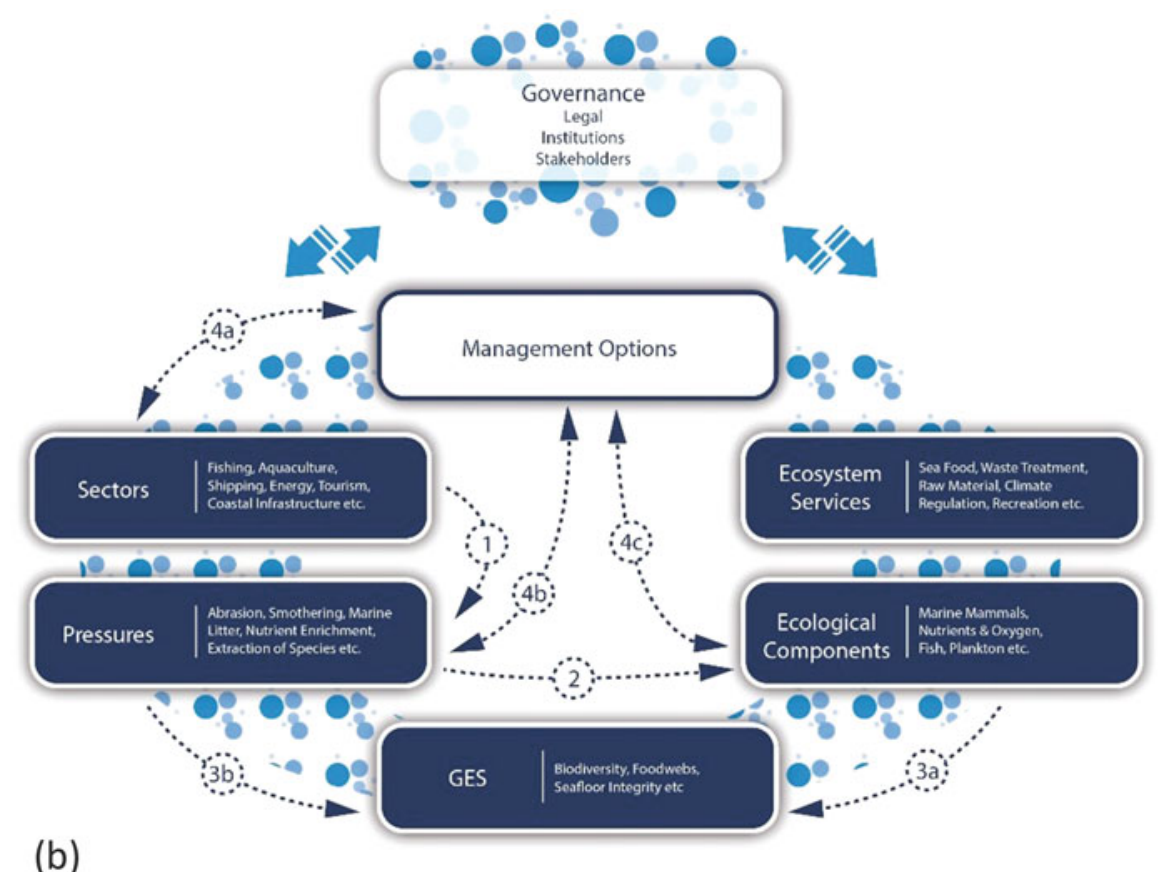

Fig. 3 The SES designed to encapsulate relevant elements that could be considered in EBM scenarios around achieving the EU's Marine Strategy Framework Directive (MSFD) objectives for Good Ecological Status (GES). In Fig. 3(a) elements (boxes) shown in dark blue are those that 
From this broad starting point, the detailed linkages between the full typologies underlying the elements of the system can be further visualised in a linkage web diagram. For example, Fig. 4 shows the links between the sectors, pressures and ecological components for the North Sea, with 4(a) showing all documented links and 4(b) only those links relevant to the pressures introduced by the fishing sector. These diagrams highlight that an activity like fishing introduces multiple pressures that ultimately can impact all parts of the ecosystem, but also that there are several pressures that are introduced by many sectors but not by fishing. These linkage web diagrams are a powerful way to illustrate the connections in systems that may be otherwise ignored, unseen or neglected. They can also be used to highlight that focussing on a single sector or pressure may not result in successful management, because there are other sectors and pressures that are concurrently having impacts on the same parts of the ecosystem (emphasizing the need for holistic EBM).

Drilling down further, participatory approaches have been developed whereby illustrations of the individual components of the typologies represented in the linkage framework are used to help engage stakeholders in a holistic exploration of the SES (e.g. Fig. 5; Robinson et al. (2019)). In a series of workshops based around European marine regional seas held in 2013, illustrated cards of the full typology of marine ecosystem services developed in Böhnke-Henrichs et al. (2013) were explored with stakeholders. Feedback suggested that many stakeholders had not previously been aware of the number and broad diversity of ecosystem services supported by marine ecosystems (Robinson et al. 2014). Stakeholders further confirmed that their views on how EBM should be implemented had changed markedly because of the visualisations provided of the full SES for their regional sea.

\section{Exploring the System-Linkages, Connectivity and Modularity}

Once the system has been defined and visualised in terms of its elements, underlying typologies and linkages, analysis of the framework can be carried out in a number of ways, using approaches borrowed from system analysis including connectance and modularity. These techniques allow simple exploration of the elements and their links in the system. Yet, useful information can emerge from this high-level consideration. For example, Knights et al. (2013) showed how network analysis of a LF covering activities, pressures and ecological characteristics could be used to identify

Fig. 3 (continued) are fundamental in terms of the assessment of the status of, and threats to, GES descriptors. Arrow 1 indicates linkages from sectors that introduce listed pressures, arrow 2 shows links from those pressures to ecological components, and arrows 3(a) and (b), those pressures and ecological components whose status is relevant to GES. Figure 3(b) adds linkages from management options to illustrate that they can act on sectors, pressures and/or on ecological components (arrows $4 \mathrm{a}-\mathrm{c}$ ) 


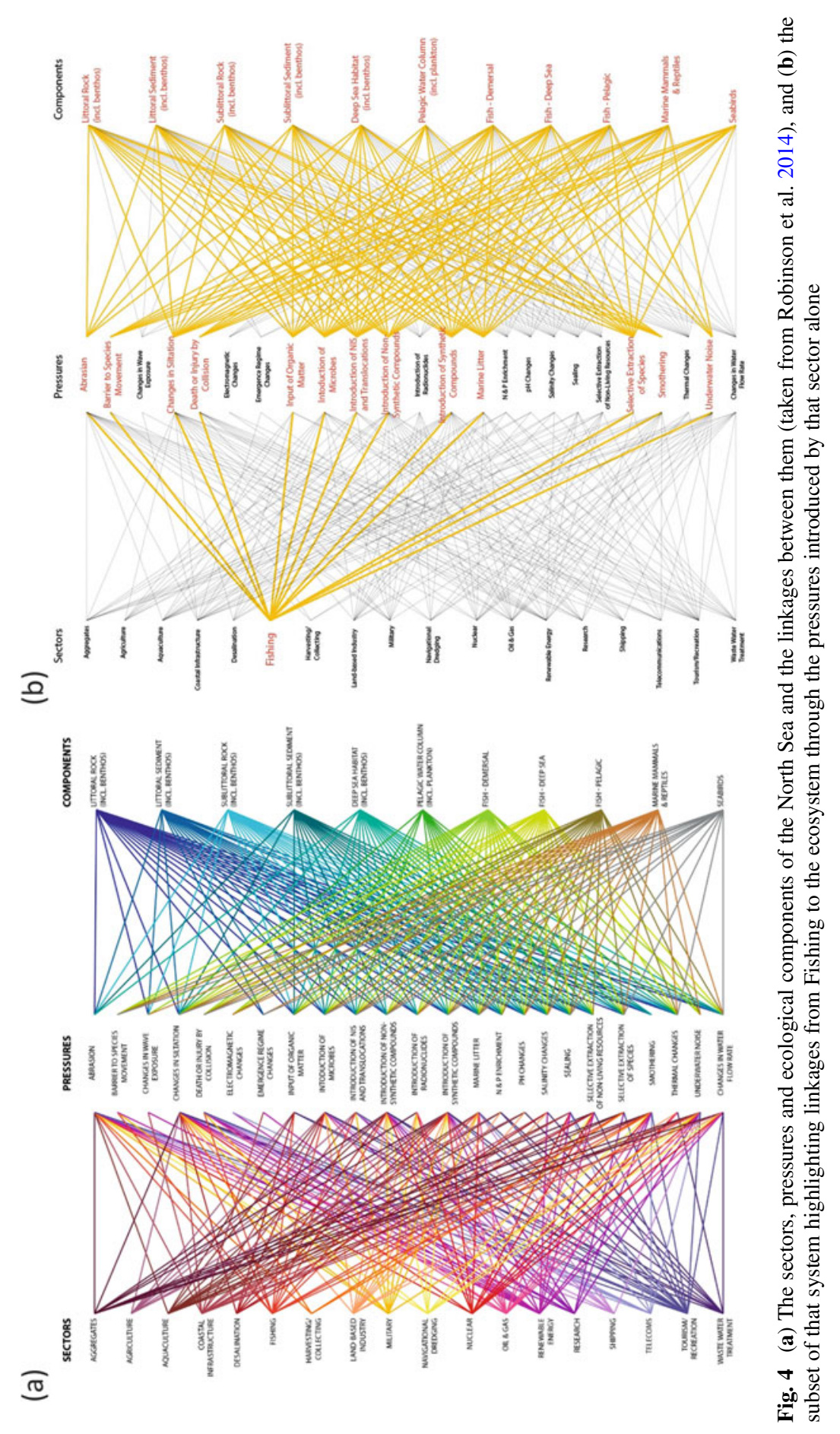



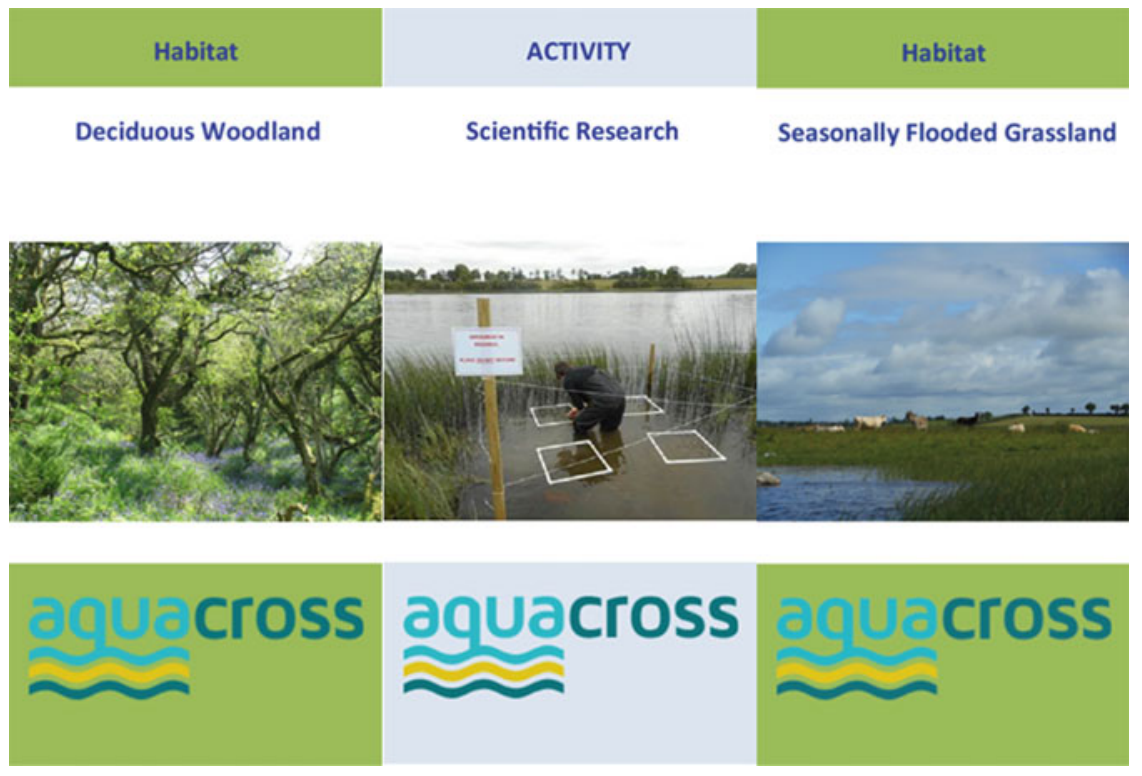

Fig. 5 An example of three cards designed to illustrate individual components of some key elements of the Lough Erne socio-ecological system in Northern Ireland (from Robinson et al. 2019)

groupings of impact chains to aid in simplification when considering EBM options. Culhane et al. (2018) went on to consider the links between marine ecosystem components and ecosystem services. They calculated connectance (Poisot and Gravel 2014), or the number of links per biotic group supplying a service as a proportion of the total number of links in the full network (Fig. 6). This revealed the importance to service supply of less charismatic species in the network e.g. bacteria. It also revealed that remote habitats are important for supporting mobile species that supply services elsewhere. This suggests that management to protect the sustainable supply of services must consider broader areas than just those where services are used.

Another technique used to explore linkage frameworks is modularity (Beckett 2016). This way of visualising links in a network highlights groups, where certain components of the system share more properties than they do with others. For example, Robinson et al. (2019) used modularity to highlight sub-sets of stakeholder goals that have similarity to each other on the basis of their interactions with activities and biodiversity that occur in Lough Erne (see also O'Higgins et al. 2020) (Fig. 7). This approach highlighted activities such as conservation, scientific research, tourism, and other recreational activities that have strongly positive associations with stakeholder goals related to biodiversity, living landscapes, and heritage (see Module A.B, Fig. 7a). On the other hand, modularity highlighted a sub-group of biodiversity components made up of invasive species perceived to negatively influence the same stakeholder goals (Module B.C, Fig. 7b) (also see 


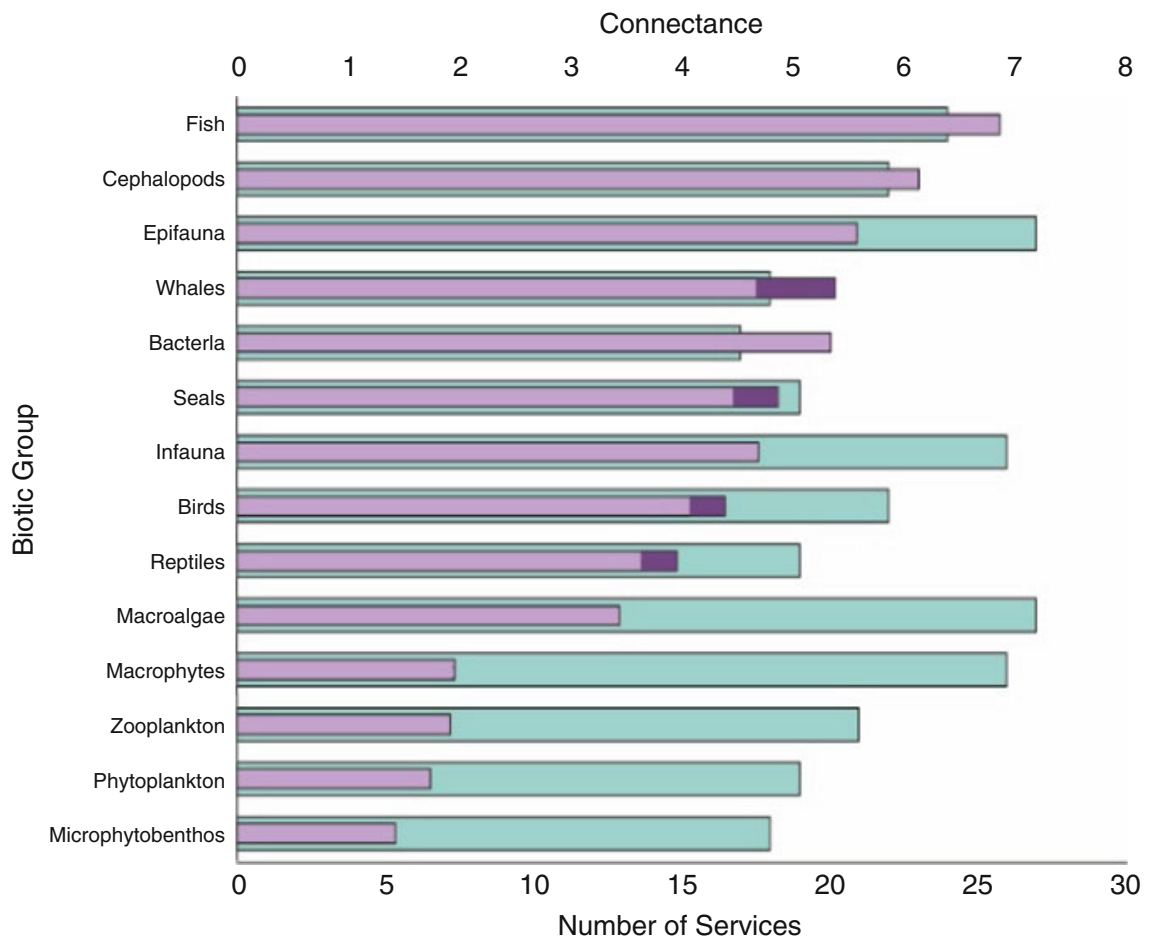

Fig. 6 The connectance (purple) and number of services (blue) supplied by each biotic group. Dark purple indicates indirect links, where a biotic group is being supported by a habitat remote from where it supplies services. (Taken from Culhane et al. 2018)

Fiona E. Culhane et al. 2018). This approach demonstrates that, although linkage frameworks are complex and contain many elements, meaningful patterns can emerge, and these patterns can be used to foster stakeholder discussion or to inform management decisions.

\section{Weighting Links-Categorical and Numerical Approaches}

Further development of the qualitative linkage framework approach is to make it semi-quantitative. Each link in the framework can be weighted according to its particular properties and how it interacts with the system. In the last example described, stakeholders in the Lough Erne system weighted typologies of activities and biodiversity, in terms of their perception of how each would affect their individual goals, using scores ranging from strongly positive to strongly negative (Robinson et al. 2019; see Fig. 7). In other approaches, weighting may be based on 


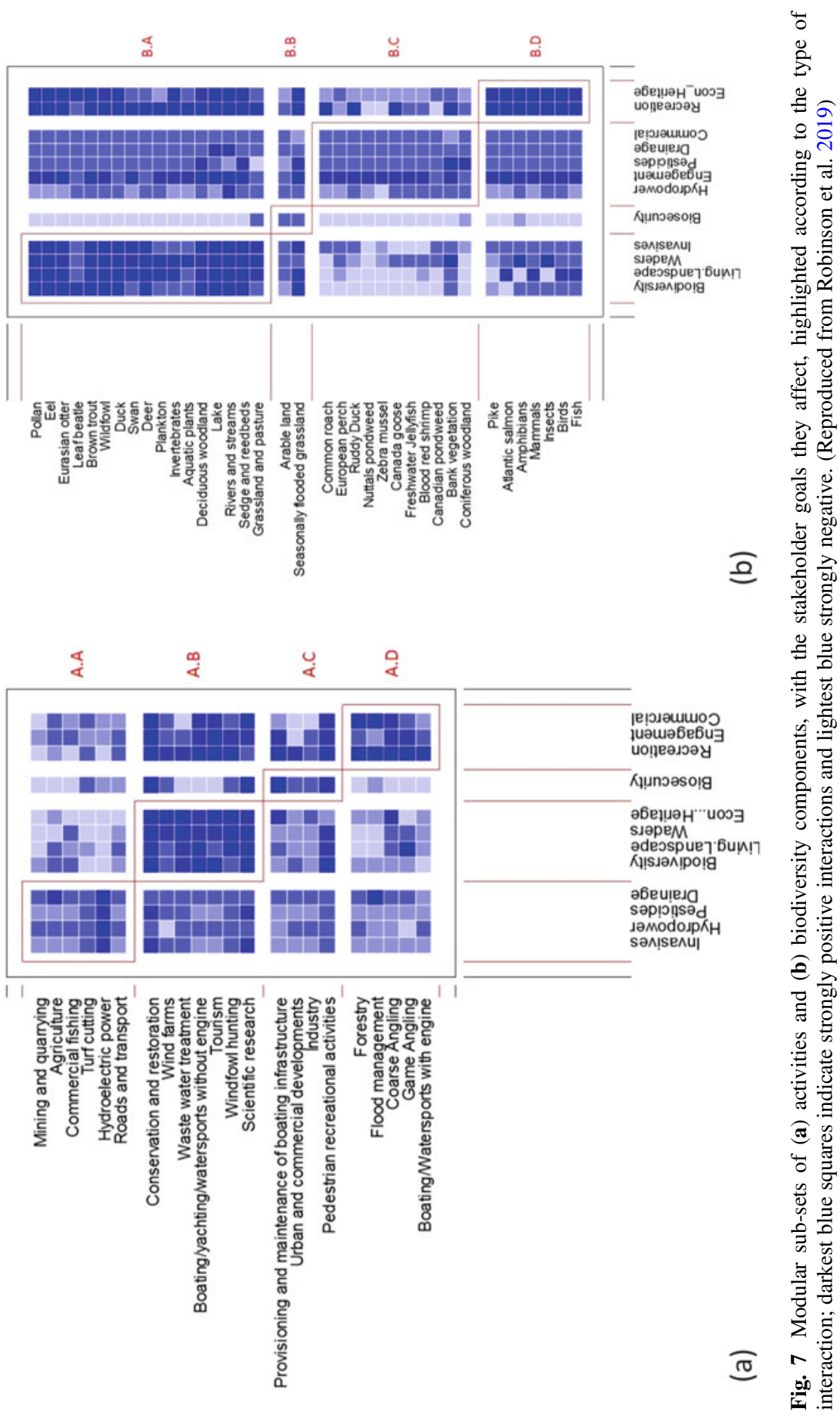


unique criteria developed to define the interactions signified by specific linkages. For example, in the ODEMM LF of European regional seas (see Figs. 1 and 3) more than 6000 linkages were identified; expert weighting of these using five categorical criteria in a structured pressure assessment approach (see Robinson et al. 2013) allowed a relative comparison of threats in the system.

A categorical approach allows exploration of the nature of interactions in the SES, because the categories used can help to shed light onto the amount and types of interactions seen. For example, Robinson et al. (in prep) were able to show that almost $10 \%$ of threats (unique linked elements, e.g. a sector, pressure and ecosystem component affected; sensu impact chains in Knights et al. 2013) in European regional seas were of the most severe threat type, and of these, just under a third are threats associated with recovery times of $>200$ years. Linkages associated with high threat characteristics can be identified and the categorical criteria used to identify, for example, sets of threats that might have greatest management potential.

Weighting can also be given a numerical value. For example, Potts et al. (2014) and Burdon et al. (2017) weighted different protected habitats and seabirds, respectively, in terms of their importance for supplying different services. Teixeira et al. (2019) built on this approach, weighting the links between parts of the ecosystem and ecosystem services based on: (1) expert judgement, taking into account how important a habitat is in supplying a particular service in a particular region (supply potential); (2) the area of that habitat (supply capacity); and (3) the condition the habitat is in (supply condition). Together, these three aspects were considered to influence the capacity for habitats to supply ecosystem services and were combined into one overall score for each habitat (Fig. 8).

As discussed earlier, the complex SES underlying EBM can be structured and visualised with a linkage framework. Weighting the LF can then be used to explore relative importance among elements in the LF, according to the criteria used, whether that is how well a habitat supplies services, or how much an activity impacts an ecological component.

\section{Linkage Frameworks and Risk Assessment for EBM}

Finally, we go on to cover how a weighted LF can be used to explore risk in a SES. Risk consists of both the exposure of the ecosystem to threats and the consequence of those threats on the ecosystem. That is, how much is an ecological component exposed to activities that introduce pressures; and what is the magnitude of those activity-pressure interactions - in terms of characteristics of the pressure and how resistant the ecosystem component may be to pressure impacts. Combining these, exposure and consequence, allows the relative degree of risk to be assessed (Knights et al. 2015). Here we particularly focus on the risk to the ecosystem and to the supply of ecosystem services, which may then go on to impact economic activities or affect other social aspects of the system in an EBM context. 

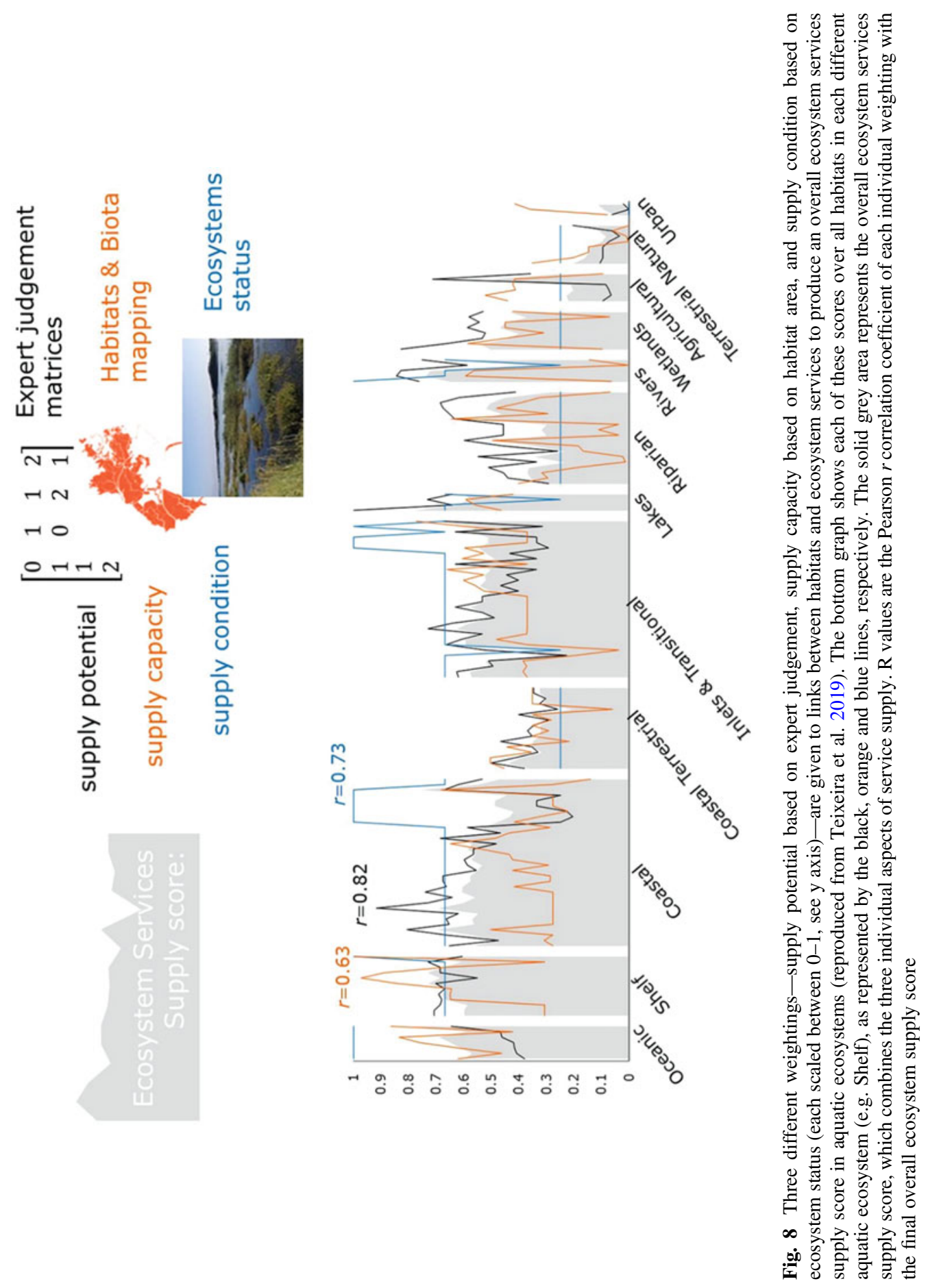
In marine environments, some risk assessment approaches have been implemented with spatial data, where habitat maps can be overlaid with maps of activities. Habitats can be given a score for their sensitivity and activities a score for the degree of impact they introduce. For example, Arkema et al. (2015) identified the relative degree of risk of coastal habitats in Belize and tested how different scenarios of future management options might result in impacts to different ecosystem services in low, medium and high risk habitats. This approach allows risk assessment to be linked to specific locations and management options. However, spatial data is often lacking in marine environments, especially at larger scales. An alternative approach is to base the risk assessment on a linkage framework, assigning scores to the weighted links, to produce a semi-quantitative risk assessment by combining scores through the LF. In this way, assessments of even large regions can be carried out. This was the approach used by Knights et al. (2015) in European regional seas and Halpern et al. (2015) in broad global assessments of risk to marine habitats.

The risk to habitats can also be determined relative to other habitats or locations. A recent example of this comes from Borgwardt et al. (2019), who looked at the impact risk across seven different European aquatic systems ranging from freshwater lakes and rivers to large marine regions (Fig. 9). They scored activity-pressure combinations for all habitats defined in an extensive linkage framework, based on five criteria: extent, frequency, persistence, severity and dispersal potential, to come up with one overall risk score for each habitat type. They reported both average and summed risk, where summed risk is greater when a habitat has more activities introducing more pressures to it.

Once the risk to habitats has been established, this can be extended to consider the risk to the supply of ecosystem services, under the assumption that ecosystem service supply is reliant on the state of the ecosystem. Using the same large, regional data, Culhane et al. (2019) linked impact risk from activities and pressures on ecosystem components with service supply potential from those ecosystem components to come up with a risk to service supply score. Overall, they found that risk is greatest in those habitats that have the greatest potential service supply (Fig. 10).

Finally, the risk scores assigned in a LF based assessment approach can then be interrogated to explore risk reduction under different EBM strategies. Piet et al. (2015) explored how different EBM measures reduced the risk to the Northeast Atlantic ecosystem, finding that measures performed differently, dependent on whether one focused on reducing past damage, present or future threats. They were able to utilise the underlying regional sea linkage framework to identify where to best target management, dependent on the focus and type of measures available. 


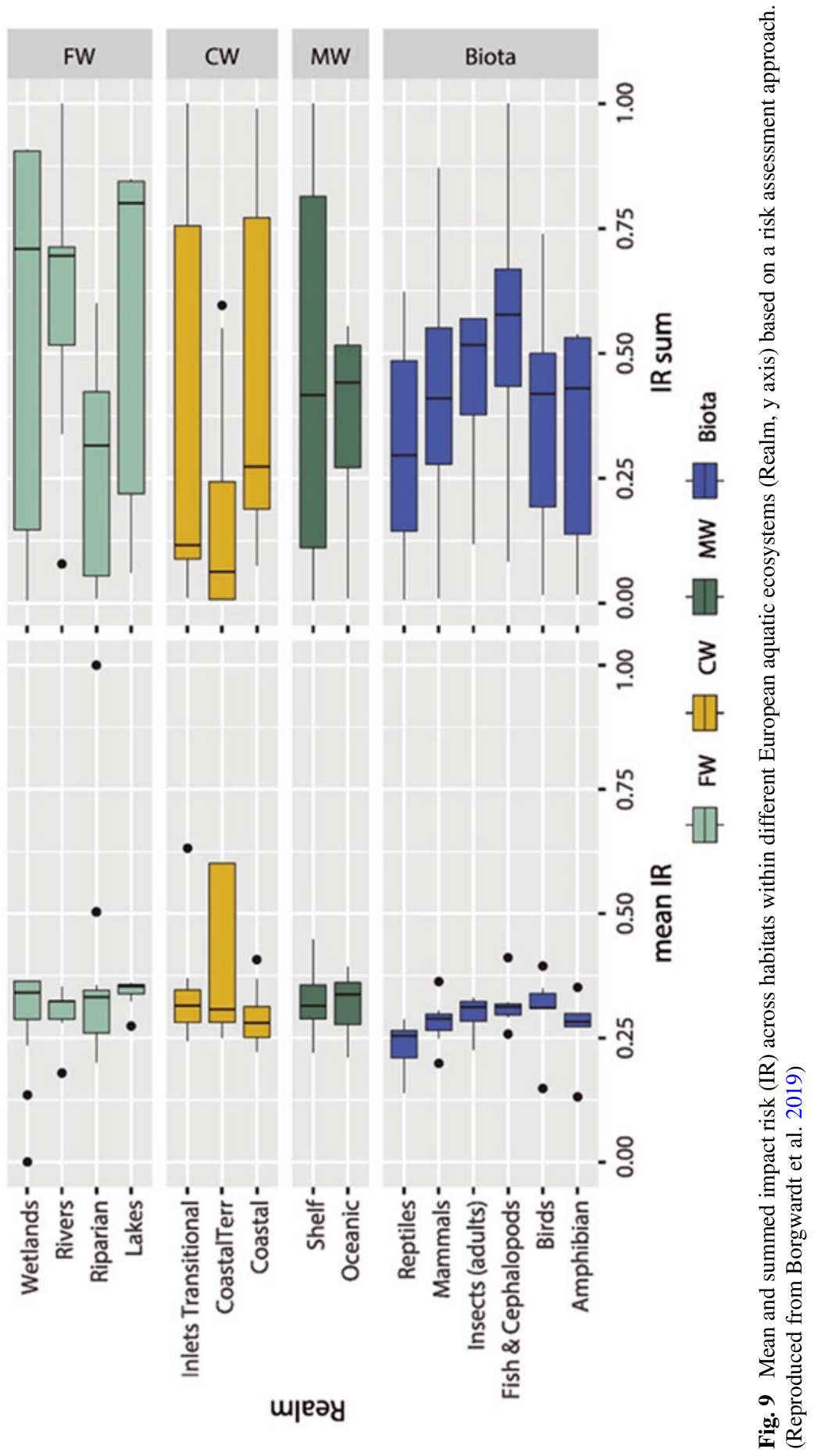




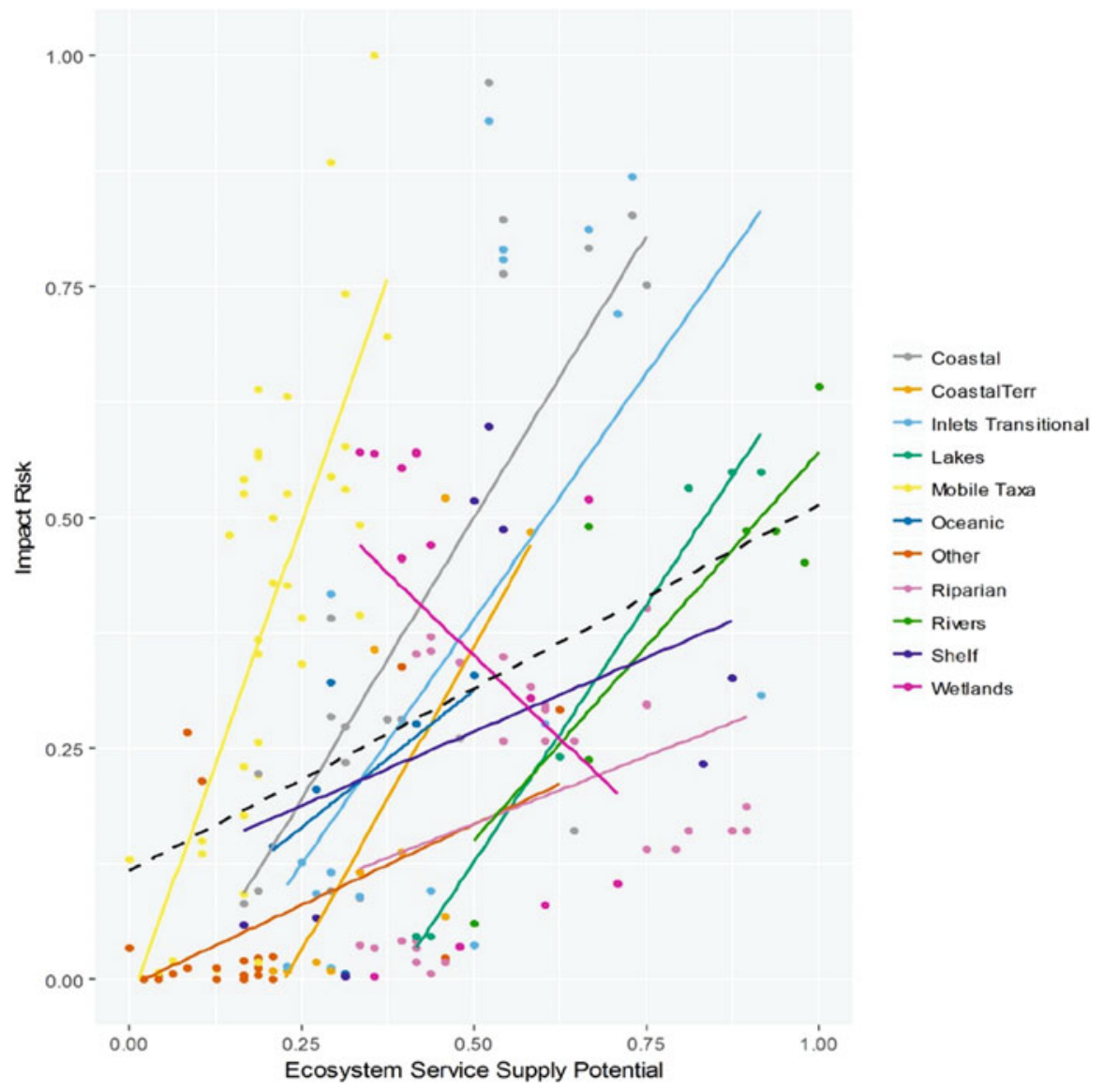

Fig. 10 The relationship between impact risk and service supply potential across different aquatic ecosystem types (shown in the key) in Europe based on a risk assessment approach. Black dashed line represents the overall relationship. (Reproduced from Culhane et al. 2019)

\section{Summary and Conclusion}

Linkage framework approaches allow a large amount of complex information, often based around expert judgement, to be formalised into an understandable structure. The LF can then be explored in various ways to answer or to provide different perspectives on EBM questions. While always considering the full complexity of SES is not possible, an LF approach goes some way to retaining this complexity and providing an overview of an SES without oversimplifying it. The approach is not data driven so can rely on a body of expert knowledge that exists amongst scientists or in the broader scientific literature. Yet, because the approach is not data driven and requires an expert knowledge base, it needs to be complemented with detailed, data driven studies to support the assumptions made. 
It is important to clearly communicate how the scope and objectives of any study has influenced the linkage framework designed, in terms of the elements included, detailed typologies used, and linkages defined. It is equally important to acknowledge that the architecture of the linkage framework used and the summation methodology approach taken in any quantitative analysis of an LF (such as in a risk assessment) will influence the results (see Piet et al. (2017) for further exploration of this). A transparent and clear explanation of these aspects helps to engender confidence in users and to generate meaningful and reliable advice for EBM decisionmaking.

In the examples explored in this chapter, only direct interactions are included in the SES studied. Further work is required to account for indirect links, which can be as, or more important, in terms of understanding unintended consequences of management actions. Likewise, analysis of weighted LFs to date, has assumed linear interactions in terms of cumulative risk, and it is well-documented that non-linear responses can be expected in SES. Both indirect effects and non-linear responses can be incorporated going forward, but further research is required to fully account for these.

\section{References}

Arkema, K. K., Verutes, G. M., Wood, S. A., Clarke-Samuels, C., Rosado, S., Canto, M., et al. (2015). Embedding ecosystem services in coastal planning leads to better outcomes for people and nature. Proceedings of the National Academy of Sciences, 112(24), 7390-7395. https://doi. org/10.1073/pnas.1406483112.

Beckett, S. J. (2016). Improved community detection in weighted bipartite networks. Royal Society Open Science, 3(1). https://doi.org/10.1098/rsos.140536.

Böhnke-Henrichs, A., Baulcomb, C., Koss, R., Hussain, S. S., \& de Groot, R. S. (2013). Typology and indicators of ecosystem services for marine spatial planning and management. Journal of Environmental Management, 130, 135-145. https://doi.org/10.1016/j.jenvman.2013.08.027.

Borgwardt, F., Robinson, L., Trauner, D., Teixeira, H., Nogueira, A. J. A., Lillebø, A. I., et al. (2019). Exploring variability in environmental impact risk from human activities across aquatic ecosystems. Science of the Total Environment, 652, 1396-1408. https://doi.org/10.1016/j. scitotenv.2018.10.339.

Burdon, D., Potts, T., Barbone, C., \& Mander, L. (2017). The matrix revisited: A bird's-eye view of marine ecosystem service provision. Marine Policy, 77, 78-89. https://doi.org/10.1016/j. marpol.2016.12.015.

Culhane, F. E., Frid, C. L. J., Royo-Gelabert, E., White, L. J., \& Robinson, L. A. (2018). Linking marine ecosystems with the services they supply: What are the relevant service providing units? Ecological Applications, 28(7), 1740-1751. https://doi.org/10.1002/eap.1779.

Culhane, F., Teixeira, H., Nogueira, A. J. A., Borgwardt, F., Trauner, D., Lillebø, A., et al. (2019). Risk to the supply of ecosystem services across aquatic ecosystems. Science of the Total Environment, 660, 611-621. https://doi.org/10.1016/j.scitotenv.2018.12.346.

Culhane, F. E., Robinson, L. A., \& Lillebø, A. I. (2020). Approaches for estimating the supply of ecosystem services for ecosystem-based management in coastal and marine environments. In T. O'Higgins, M. Lago, \& T. H. DeWitt (Eds.), Ecosystem-based management, ecosystem services and aquatic biodiversity: Theory, tools and applications (pp. 105-126). Amsterdam: Springer. 
EC. (2008). Establishing a framework for community action in the field of marine environmental policy (Marine Strategy Framework Directive). Directive 2008/56/EC of the European Parliament and of the Council. Official Journal of the European Communities, L164, 19-40.

Elliott, M., \& O'Higgins, T. G. (2020). From the DPSIR, the D(A)PSI(W)R(M) emerges... a butterfly-'protecting the natural stuff and delivering the human stuff'. In T. O'Higgins, M. Lago, \& T. H. DeWitt (Eds.), Ecosystem-based management, ecosystem services and aquatic biodiversity: Theory, tools and applications (pp. 61-86). Amsterdam: Springer.

Game, E. T., Meijaard, E., Sheil, D., \& McDonald-Madden, E. (2014). Conservation in a wicked complex world; challenges and solutions. Conservation Letters, 7(3), 271-277. https://doi.org/ 10.1111/conl.12050.

Haines-Young, R., \& Potschin, M. (2013). Common International Classification of Ecosystem Services (CICES): Consultation on Version 4, August-December 2012, EEA Framework Contract No. EEA/IEA/09/003.

Haines-Young, R., \& Potschin, M. (2018). Common International Classification of Ecosystem Services (CICES) V5.1 and guidance on the application of the revised structure. Retrieved from www.cices.eu.

Halpern, B. S., Frazier, M., Potapenko, J., Casey, K. S., Koenig, K., Longo, C., et al. (2015). Spatial and temporal changes in cumulative human impacts on the world's ocean (Article). 6, 7615. https://doi.org/10.1038/ncomms8615. Retrieved from https://www.nature.com/articles/ ncomms8615\#supplementary-information.

Knights, A. M., Koss, R. S., \& Robinson, L. A. (2013). Identifying common pressure pathways from a complex network of human activities to support ecosystem-based management. Ecological Applications, 23(4), 755-765. https://doi.org/10.1890/12-1137.1.

Knights, A. M., Piet, G. J., Jongbloed, R. H., Tamis, J. E., White, L., Akoglu, E., et al. (2015). An exposure-effect approach for evaluating ecosystem-wide risks from human activities. ICES Journal of Marine Science, 72(3), 1105-1115. https://doi.org/10.1093/icesjms/fsu245.

Mitchell, M. (2009). Complexity: A guided tour. New York: Oxford University Press.

O’Higgins, T. G., Culhane, F., O'Dwyer, B., Robinson, L., \& Lago, M. (2020). Combining methods to establish potential management measures for invasive species Elodea nutallii in Lough Erne Northern Ireland. In T. O'Higgins, M. Lago, \& T. H. DeWitt (Eds.), Ecosystembased management, ecosystem services and aquatic biodiversity: Theory, tools and applications (pp. 445-460). Amsterdam: Springer.

Piet, G. J., Jongbloed, R. H., Knights, A. M., Tamis, J. E., Paijmans, A. J., van der Sluis, M. T., et al. (2015). Evaluation of ecosystem-based marine management strategies based on risk assessment. Biological Conservation, 186, 158-166. https://doi.org/10.1016/j.biocon.2015.03.011.

Piet, G. J., Knights, A. M., Jongbloed, R. H., Tamis, J. E., de Vries, P., \& Robinson, L. A. (2017). Ecological risk assessments to guide decision-making: Methodology matters. Environmental Science \& Policy, 68, 1-9. https://doi.org/10.1016/j.envsci.2016.11.009.

Piet, G., Delacámara, G., Kraan, M., Röckmann, G. C., \& Lago, M. (2020). Advancing aquatic ecosystem-based management with full consideration of the social-ecological system. In T. O'Higgins, M. Lago, \& T. H. DeWitt (Eds.), Ecosystem-based management, ecosystem services and aquatic biodiversity: Theory, tools and applications (pp. 17-38). Amsterdam: Springer.

Poisot, T., \& Gravel, D. (2014). When is an ecological network complex? Connectance drives degree distribution and emerging network properties. PeerJ, 2, 251.

Potts, T., Burdon, D., Jackson, E., Atkins, J., Saunders, J., Hastings, E., et al. (2014). Do marine protected areas deliver flows of ecosystem services to support human welfare? Marine Policy, 44, 139-148. https://doi.org/10.1016/j.marpol.2013.08.011.

Rittel, H. W. J., \& Webber, M. M. (1973). Dilemmas in a general theory of planning. Policy Sciences, 4(2), 155-169. https://doi.org/10.1007/bf01405730.

Robinson, L. A., White, L. J., Culhane, F. E., \& Knights, A. M. (2013). ODEMM pressure assessment userguide V.2. ODEMM Guidance Document Series No. 4. EC FP7 project (244273) 'Options for Delivering Ecosystem-based Marine Management' (12 pp.). University of Liverpool. ISBN: 978-0-906370-86-5. 
Robinson, L. A., Culhane, F. E., Baulcomb, C., Bloomfield, H., Boehnke-Henrichs, A., Breen, P., et al. (2014). Towards delivering ecosystem-based marine management: The ODEMM approach. Deliverable 17, EC FP7 project (244273) 'Options for Delivering Ecosystem-based Marine Management' (96 pp.). University of Liverpool. ISBN: 978-0-906370-89-6.

Robinson, L. A., Blincow, H. L., Culhane, F. E., \& O’Higgins, T. (2019). Identifying barriers, conflict and opportunity in managing aquatic ecosystems. Science of the Total Environment, 651, 1992-2002. https://doi.org/10.1016/j.scitotenv.2018.10.020.

Teixeira, H., Lillebø, A. I., Culhane, F., Robinson, L., Trauner, D., Borgwardt, F., et al. (2019). Linking biodiversity to ecosystem services supply: Patterns across aquatic ecosystems. Science of the Total Environment, 657, 517-534. https://doi.org/10.1016/j.scitotenv.2018.11.440.

White, L. J., Koss, R., Eriksson, A., \& Robinson, L. A. (2013). ODEMM linkage framework userguide (Version 2). ODEMM Guidance Document Series No. 3. EC FP7 project (244273) 'Options for Delivering Ecosystem-based Marine Management' (14 pp.). University of Liverpool. ISBN: 978-0-906370.

Yodzis, P. (2001). Must top predators be culled for the sake of fisheries? Trends in Ecology \& Evolution, 16(2), 78-84. https://doi.org/10.1016/S0169-5347(00)02062-0.

Open Access This chapter is licensed under the terms of the Creative Commons Attribution 4.0 International License (http://creativecommons.org/licenses/by/4.0/), which permits use, sharing, adaptation, distribution and reproduction in any medium or format, as long as you give appropriate credit to the original author(s) and the source, provide a link to the Creative Commons licence and indicate if changes were made.

The images or other third party material in this chapter are included in the chapter's Creative Commons licence, unless indicated otherwise in a credit line to the material. If material is not included in the chapter's Creative Commons licence and your intended use is not permitted by statutory regulation or exceeds the permitted use, you will need to obtain permission directly from the copyright holder.

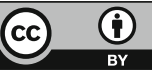

